\title{
Exploring Relationships Among Responsibilities of Mathematics Coaches and Specialists and Student Achievement
}

\author{
Kristin E. Harbour ${ }^{1 \star}(\mathbb{D})$, Evthokia S. Saclarides ${ }^{2}$ (D), Jill L. Adelson ${ }^{3}$ (D) Karen S. Karp $^{4}$ (D)
}

\author{
${ }^{1}$ University of South Carolina, Columbia, SC, USA \\ ${ }^{2}$ University of Cincinnati, Cincinnati, OH, USA \\ ${ }^{3}$ Adelson Research \& Consulting, LLC, Durham, NC, USA \\ ${ }^{4}$ Johns Hopkins University, Baltimore, MD, USA \\ *Corresponding Author: kharbour@mailbox.sc.edu
}

Citation: Harbour, K. E., Saclarides, E. S., Adelson, J. L., \& Karp, K. S. (2021). Exploring Relationships Among Responsibilities of Mathematics Coaches and Specialists and Student Achievement. International Electronic Journal of Mathematics Education, 16(2), em0640. https://doi.org/10.29333/iejme/10907

\section{ARTICLE INFO}

Received: 7 Jan. 2021

Accepted: 19 Mar. 2021

\begin{abstract}
In this study, we used hierarchical linear modeling to examine restricted-use 2011 National Assessment of Educational Progress (NAEP) data to explore relationships between principal-reported time spent on the different NAEP responsibilities of mathematics coaches and specialists (MCSs) and the achievement scores of approximately 37,400 fourth-grade students in 1,500 U.S. elementary schools. The model included adjustments for composite covariates, control variables, and sampling weights. Significant relationships between principalreported time spent on six different NAEP-defined responsibilities provided by full-time MCSs and fourth-grade students' mathematics achievement were observed, including relationships between achievement and MCSs assisting both teachers and students. Implications for the effective use of MCSs in schools and suggestions for future research are discussed.
\end{abstract}

Keywords: mathematics coach, mathematics specialist, elementary, mathematics achievement

\section{INTRODUCTION}

As a focus on improving students' understanding of and performance in mathematics is of high priority for multiple stakeholders, many U.S. districts and schools have turned to mathematics coaches and specialists to support these changes (e.g., Fennell, 2017; National Mathematics Advisory Panel [NMAP], 2008). Although the terms mathematics coach and mathematics specialist are defined invariably (NMAP, 2008), in general, a mathematics coach directly engages with teachers by providing professional development (PD), while a mathematics specialist engages with students (McGatha et al.2015). For the purposes of our study, we use the term MCSs to refer to mathematics coaches and specialists ${ }^{1}$. To accommodate the increased presence of MCSs in U.S. schools, many states have created state certifications for MCSs (McGatha et al., 2015; Rigelman \& Wray, 2017), and some institutions of higher education have focused attention on how to effectively train MCSs (Goodman et al., 2017; Harrington et al., 2017; Haver et al., 2017; Strutchens \& Martin, 2017).

Indeed, there seems to be much optimism about MCSs' potential to support the teaching and learning of mathematics for several reasons. The rationale for MCSs' use is built upon foundational research on effective PD. That is, MCSs are thought to embody tenets of high-quality PD, such as providing ongoing, focused, and interactive learning experiences for teachers (Desimone \& Pak, 2017; Gibbons \& Cobb, 2017). By relying on these tenets, MCSs may be the key to changing teachers' instructional practices. Furthermore, there is a growing body of research that points to the positive impact that MCSs can have on teachers (Baldinger, 2014; Gibbons, Kazemi, Hintz, \& Hartmann, 2017; Gibbons, Kazemi, \& Lewis, 2017; Munson, 2017; Polly, 2012) and students (Campbell \& Malkus, 2011; Ellington, et al., 2017; Harbour et al., 2018). By providing on-going, job-embedded support for teachers, MCSs have the potential to enhance students' access to high-quality mathematics teaching and learning (Campbell \& Malkus, 2011; Chval et al., 2010; Fennell, 2017; Polly et al., 2013).

MCSs often take on many responsibilities within a school or district (Mudzimiri et al., 2014), varying by the context of their work (Fennell, 2017; McGatha \& Rigelman, 2017). For example, MCSs may provide PD to individuals (Barlow et al., 2014; Neuberger, 2012; Obara \& Sloan, 2009; Polly, 2012), and/or groups of teachers (Elliott et al., 2009; Gibbons, Kazemi, Hintz, \& Hartmann, 2017;

\footnotetext{
${ }^{1}$ As the 2011 National Association of Educational Progress (NAEP) Mathematics Assessment data specifically uses the words coach and/or specialist, we will use these terms throughout our paper for consistency.
} 
Gibbons, Kazemi, \& Lewis, 2017; Hopkins et al., 2017; Lesseig et al., 2017). Furthermore, while engaged in PD with teachers, MCSs may facilitate the implementation of school, district, or state initiatives; the use of assessment data; the integration of researchbased instructional practices; and the selection of high-quality curriculum materials (Campbell \& Malkus, 2011; Chval et al., 2010; Fennell, 2017; Hopkins et al., 2017; Neufeld \& Roper, 2003; Polly et al., 2013). MCSs' responsibilities may also encompass working directly with students to enhance student understanding of and achievement in mathematics (Chval et al., 2010; Fennell, 2017; Gerretson et al., 2008; Webel et al., 2017).

While there seems to be a growing body of research describing MCSs' responsibilities, there is little research that links MCSs' responsibilities not only to teacher change but also to student achievement. Hence, the purpose of this study is to better understand the relationship among full-time MCSs' responsibilities and fourth-grade students' mathematics achievement.

\section{LITERATURE REVIEW}

The literature review begins by discussing how we theorized MCSs as a support for the teaching and learning of mathematics. Next, we turn to summarize the literature describing MCSs' two primary responsibilities when directly supporting teaching and learning 2 : to work with teachers and/or students.

\section{Theorizing MCSs as a Support for Teaching and Learning}

The current study draws upon the cognitive apprenticeship model of learning (Collins et al., 1987) as a theoretical backdrop for understanding how MCSs engage with teachers and students. Accordingly, MCSs are the instructional experts that guide and support the metacognitive and cognitive learning of the less experienced novice (e.g., teacher or student) in a cooperative and interactive environment. Three scaffolded teaching methods are foundational to this model, forming the basis for coach-teacher and coach-student relationships: modeling, coaching, and fading (Collins et al., 1987). During the modeling phase, the expert continuously models the targeted task, skill or process while externalizing their cognitive processes (which are typically internalized). In doing so, the novice obtains an exemplary image of the intended task, skill or process. During the coaching phase, which is meant to be more interactive, the novice takes on responsibility for enacting the desired task, skill, or process, while still receiving guidance from the expert. During the last phase - fading - the coach decreases their involvement and provides limited suggestions and feedback to the novice. We note that these three teaching methods are not meant to be executed in a fixed sequence, and instead must be fully integrated into practice.

According to Collins and colleagues (1987), this model is directly applicable in elementary subjects that are foundational, including mathematics. That is, the metacognitive and cognitive skills needed for content areas, including mathematics, are "foundational not only because they provide the basis for learning and communication in other school subjects, but also because...the processes are basic to learning and thinking more generally" (Collins et al., 1987, p. 7). Given the cognitive apprenticeship learning model's explicit connection to mathematics, this theoretical model provides a productive lens for exploring the work of MCSs.

\section{MCSs and Teacher Change}

Qualitative and quantitative research alike have discovered positive relationships between enhanced mathematics instruction and MCSs (e.g., Alloway \& Jilk, 2010; Baldinger, 2014; Campbell, 1996; Munson, 2017; Neuberger, 2012; Polly, 2012; Race et al., 2002; Rudd et al., 2009). Although most studies show MCSs' potential to positively influence teachers' instructional practices, results are influenced by the intent of the coach's role and/or type of the coach (e.g., Becker, 2001; McGatha, 2008), as well as teachers' varying experiences and conceptions of how mathematics should be taught (e.g., Ai \& Rivera, 2003; Olson \& Barrett, 2004).

One group of studies found that by implementing a mathematics coaching component as part of a large-scale professional development program, teachers made noteworthy changes in their instruction (Alloway \& Jilk, 2010; Campbell, 1996; Race et al., 2002). Specifically, teachers reportedly increased their variety and use of effective instructional practices (Race et al., 2002), engaged students in developing an in-depth understanding of mathematics (Campbell, 1996), and used their planning time in a more focused way and successfully generalized their experiences to other contexts (Alloway \& Jilk, 2010).

Further support for mathematics coaching was observed in a collection of small-scale, qualitative studies involving one-onone coaching (Baldinger, 2014; Munson, 2017; Neuberger, 2012; Obara \& Sloan, 2009; Polly, 2012; Rudd et al., 2009). Findings indicate that through individual coaching, teachers increased their use of research-based practices (Munson, 2017; Obara \& Sloan, 2009; Polly, 2012; Rudd et al., 2009) and changed their beliefs about high-quality mathematics teaching (Neuberger, 2012).

In addition to one-on-one coaching, there is growing evidence that points to group coaching as a productive way in which MCSs may interact with teachers (Elliott et al., 2009; Gibbons, Kazemi, Hintz, \& Hartmann, 2017; Gibbons, Kazemi, \& Lewis, 2017; Hopkins, et al., 2017; Lesseig et al., 2017). In particular, findings demonstrate that group coaching may provide teachers with opportunities to deepen their mathematical understanding (Elliott et al., 2009; Gibbons, Kazemi, Lewis, 2017; Lesseig et al., 2017), as well as engage in pedagogical discussions about student reasoning (Gibbons, Kazemi, Lewis, 2017) and/or how to analyze student data (Hopkins et al., 2017).

\footnotetext{
${ }^{2}$ We acknowledge that coaches have a host of other responsibilities that are not directly related to supporting teaching and learning (e.g., Chval et al., 2010; Kane \& Rosenquist, 2018; Matsumura et al., 2009; Saclarides \& Lubienski, 2020). However, as those activities are not the focus of the current paper or data set, we will not explore those responsibilities here.
} 
Additional, qualitative research has generally found positive results regarding the relationship between mathematics coaches and changes in teachers' instructional practices, however, the results seemed to be influenced by the intent of the coach's role and/or type of the coach (Becker, 2001; McGatha, 2008). For example, Becker (2001) found that the most directive approach to coaching - coach as leader - may be the most effective in deepening teachers' pedagogical and mathematics content knowledge. Building upon this work, McGatha (2008) found that as coaches progressed from the role of consultant, to collaborator, and/or to coach, the coach and teacher found the shared experience more valuable.

The prior research discussed indicates a positive relationship between MCSs and changes in teachers' instructional practices. There are a handful of studies, however, that indicate mixed results (Ai \& Rivera, 2003; Olson \& Barrett, 2004). For example, Olson and Barrett (2004) found that although their participating teachers became more aware of students' construction of mathematical ideas while working with a coach, the teachers persisted in using traditional approaches in their mathematics instruction. Furthermore, Ai and Rivera (2003) found an inconsistency in teachers' positive views of coaching and their instructional practice on a mathematics evaluation survey; this inconsistency showed that teachers' positive self-perceptions may not have actually translated into improved instruction.

Summary of MCSs and teacher change. Overall, research on MCSs largely focuses on the influence coaching has on teachers' beliefs and instructional practices. Studies from large-scale PD projects that utilize coaches to small-scale case studies have documented the positive influence MCSs have on teachers' efforts to improve instruction and incorporate research-based strategies into their classrooms. Although the majority of studies view MCSs' work as influencing positive changes in mathematics instruction, there are studies that have noted limited changes in teachers' practices after working with an MCS.

\section{MCSs and Student Achievement}

The link between student achievement and MCSs is critical; however, there is limited research that supports this important relationship. One group of studies explored relationships between MCSs and student achievement when coaching was embedded within a larger professional development or reform effort (Balfanz et al., 2006; Campbell, 1996; Foster \& Noyce, 2004). For instance, Balfanz et al. (2006) provided evidence of the connection between coaching as nested within a whole-school reform effort and increases in student mathematics achievement over four years. Hierarchical linear modeling from fourth-year data revealed that students in the three treatment middle schools performed significantly higher on standardized and state assessments than students in the three control middle schools.

Although results from the previous group of studies provide much needed evidence of the link between coaching and enhanced student mathematics achievement, one limitation is the difficulty in showing the specific effects of the coaching, as opposed to the effects of the overall reform initiative. A small body of research has begun to address this limitation (Campbell \& Malkus, 2011; Ellington et al., 2017; Harbour et al., 2018). To illustrate, in their study using restricted-use data from the 2011 NAEP mathematics assessment, Harbour and colleagues (2018) found significant and positive relationships between the use of full-time MCSs and fourth-graders' overall mathematics achievement, as well as their achievement across all five NAEP-defined mathematics content areas. Conversely, this positive relationship was not found for part-time MCSs. Additionally, this work explored how the relationship of having a MCS in their elementary school related to the mathematics achievement for students with and without disabilities, finding that the relationship did not differ based on students' disability status.

Summary of MCSs and student achievement. The link between the use of MCSs and student achievement is essential when examining the overall impact of MCS, and yet this link has only been tentatively established by a handful of research studies. Although the evidence reported is consistently positive, continued research that substantiates and builds upon the current base is needed to further establish this link.

\section{PURPOSE AND RESEARCH QUESTION}

To determine how MCSs' various responsibilities relate to fourth-grade students' mathematics achievement, the current study focused on the following research question:

For elementary schools who indicated having a full-time MCS, how does principal-reported time spent on the six different responsibilities, which include providing assistance to teachers and students (see Table 1 for a complete list of the six responsibilities), relate to fourth-grade students' achievement, specifically: a) their overall mathematics achievement? and b) their achievement in five specific mathematics content areas (i.e., number properties and operations; measurement; geometry; data analysis, statistics, and probability; and algebra)?

The purpose of these analyses is to begin delving deeper into the question of how and what should MCSs be engaged in during their work in schools to potentially influence students' mathematical understanding and performance. 
Table 1. Descriptive Statistics for the Responsibilities of Mathematics Coach/Specialist as Defined in the 2011 NAEP Dataset

\begin{tabular}{|c|c|c|}
\hline \multicolumn{3}{|c|}{ Responsibilities of the Mathematics Coach/Specialist } \\
\hline ID & Variable Description & Mean (SD)* \\
\hline C071401 (Responsibility 1) & $\begin{array}{c}\text { Provide technical assistance/support to individual teachers about mathematics content or the } \\
\text { teaching of mathematics }\end{array}$ & $2.72(0.92)$ \\
\hline C071402 (Responsibility 2) & $\begin{array}{c}\text { Conduct professional development for groups of teachers about mathematics content or the } \\
\text { teaching of mathematics }\end{array}$ & $2.01(1.05)$ \\
\hline C071403 (Responsibility 3) & Provide mathematics instruction to students on various topics & $2.06(0.97)$ \\
\hline C071404 (Responsibility 4) & Provide mathematics instruction to students at various grade levels & $2.03(1.01)$ \\
\hline C071405 (Responsibility 5) & Provide mathematics remediation/intervention to some student groups & $2.04(1.04)$ \\
\hline C071406 (Responsibility 6) & Provide mathematics enrichment to some student groups & $1.36(1.06)$ \\
\hline
\end{tabular}

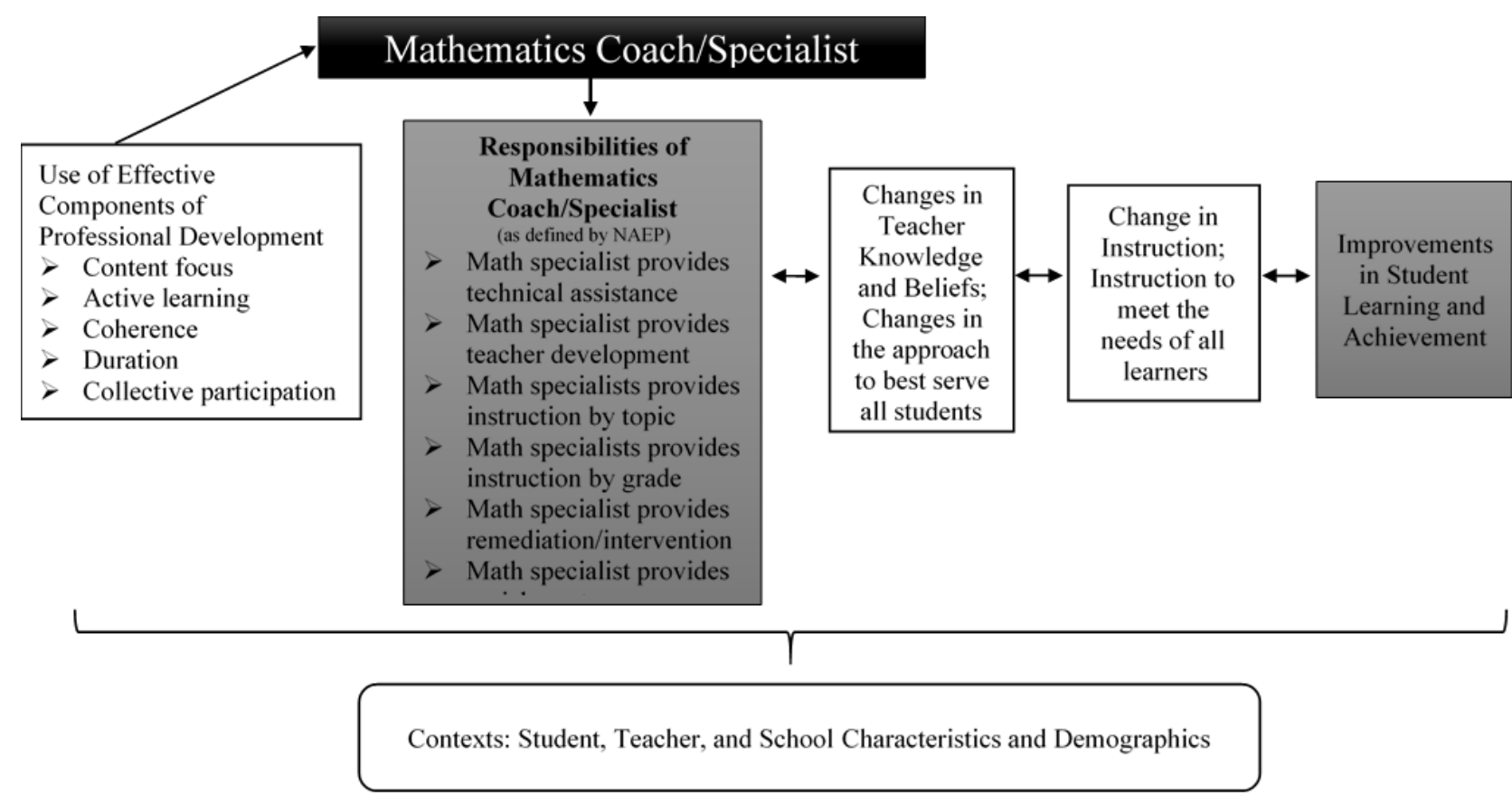

Figure 1. Conceptual Framework for Examining the Relationship between Mathematics Coaches and Specialists and Fourth-Grade Students' Mathematics Achievement. The conceptual framework used for the current study draws upon Desimone's (2009) model for "studying the effects of professional development on teachers and students" (p. 185) and Campbell and Malkus's (2011) model for "studying the impact of elementary mathematics coaches on teachers and students" (p. 433). The highlighted boxes designate the scope of the current research project. Additionally, the contextual factors (i.e., student, teacher, and school during-treatment covariates) are controlled for during analyses.

\section{CONCEPTUAL FRAMEWORK}

Our conceptual framework draws upon Desimone's (2009) model for studying the impact of PD on students and teachers, as well as Campbell and Malkus's (2011) model exploring MCSs' impact on teachers and students (see Figure 1). Desimone's (2009) model helps establish links between core features of effective PD; changes in teachers' beliefs, knowledge, and instruction; and changes in students' learning and achievement. Campbell and Malkus (2011) modified Desimone's (2009) model to incorporate MCSs as a form of high-quality PD. According to them, MCSs (nested within larger PD programs) help spur changes in teachers' instructional practices as well as improvements in students' achievement and learning.

As illustrated in Figure 1, we have combined attributes from these two models to create a conceptual framework that serves as a roadmap for our study. There are several parts we wish to highlight. First, the highlighted boxes designate the scope of the current research project. That is, we wish to explore the relationship between MCSs' responsibilities (as defined by NAEP) and improvements in student mathematics learning and achievement. Second, the contextual factors (e.g., student, teacher, and school during-treatment covariates) are controlled for during analyses, which we discuss further in the Method section. 


\section{METHOD}

\section{Sample}

The sample in this study is drawn from students who participated in the fourth grade 2011 NAEP Mathematics Assessment and whose data were included in the restricted-use dataset, which included assessments from approximately 209,000 fourth-grade students across approximately 8,500 elementary schools (NCES, 2011, 2013). Prior research using the same NAEP dataset found that the presence of full-time MCSs in public and private elementary schools was positively, statistically significantly related to fourth-grade student mathematics achievement (Harbour et al., 2018); therefore, the current study limited the scope of the sample to include only elementary schools that indicated having a full-time MCS through the school survey and to all students from those schools. Of the total elementary school sample, approximately $18.8 \%$ of elementary schools reported having a full-time MCS. Specifically, the unweighted school sample with full-time MCSs was approximately 1,500 elementary schools, with a weighted ${ }^{3}$ sample of approximately 9,080 elementary schools. The unweighted student sample included approximately 37,400 fourth-grade students, with a weighted sample of approximately 694,970 fourth-grade students. (Note: All unweighted sample sizes have been rounded to the nearest 10 per NCES requirements).

\section{Data Sources}

2011 NAEP Grade 4 Mathematics Assessment. The NAEP fourth-grade mathematics assessment included 158 questions of multiple formats (i.e., multiple choice, short constructed response, and extended constructed response) across five content areas, with varying weight given to each content area: number properties and operations (40\%); measurement (20\%); geometry (15\%); data analysis, statistics, and probability (10\%); and algebra (15\%; NCES, 2011, p. 6). Given the large number of questions, the assessment was subdivided into smaller sections to allow students to only have 15-19 questions (NCES, 2013). Matrix sampling and item response theory were used to ensure a representative sample of students took the smaller portion of the assessment and to estimate average scale scores for overall mathematics achievement (i.e., composite score) and content area scores, respectively. Performance scores were reported on a 0-500 point scale, with each student receiving five plausible value scores for each domain and composite score due to the matrix sampling procedures.

MCS Responsibilities. The extent to which MCSs engaged in the various NAEP-defined responsibilities (see Table 1) was a school-level variable reported by the principal or vice principal of each elementary school. The extent to which the six responsibilities presented were available to their school's fourth-grade students and their teachers was measured on a scale ranging from "not at all" to a "large extent" (NCES, 2013). The recoded scale for extent to which the activity was performed is as follows: 0 = not at all, 1 = small extent, 2 = moderate extent, and $3=$ large extent. One response per responsibility was requested on the questionnaire.

Composite covariates and additional control variables. Prior to any analyses, we cleaned the data by creating dummy codes for categorical variables, identifying and appropriately coding missing data, and recoding interval and ratio data to have a meaningful zero (e.g., subtracting 1 from the value so that the range started at 0 rather than 1). After data clean-up, we identified potential during-treatment control variables by examining the correlations between theoretically-important student-level variables that represent both student and teacher information and (a) the outcome (i.e., fourth-grade mathematics achievement composite scores) and (b) the treatment (i.e., having a full-time MCS). Similarly, we identified potential during-treatment control variables at the school level by examining the correlations between theoretically-important school-level variables that were either collected from the NAEP school survey or aggregated from student-level student and teacher variables and (a) the outcome and (b) the treatment. The variables at each level (student and school) that had a statistically significant relationship with the outcome or the treatment variables were considered during-treatment covariates.

Having identified 16 during-treatment student covariates (e.g., students' mathematics self-efficacy, students' attitudes towards mathematics) and 30 during-treatment teacher covariates (e.g., teachers' instructional and assessment practices, teachers' degree of emphasis on certain mathematics content strands) that were both theoretically-important and statistically significantly related to either the outcome or treatment (or both), we next sought parsimony and decreased multicollinearity in our model by using principal components analysis (PCA; Stevens, 2009). We conducted PCA with oblimin rotation for student covariates and then a separate PCA for teacher covariates. To determine the number of components, we used multiple criteria (i.e., eigenvalues greater than 1.0, scree plots, and parallel analysis), and we eliminated any variable that loaded on its component at less than 0.4 (Stevens, 2009). Once we followed this process to create composite scores to use as controls in our models, we examined the reliability of the weighted items for each composite, and we did not include any composite with a reliability less than .70. Student and teacher composite variables and their reliabilities are included in Table 2.

After determining the composite variables, we created factor scores using the regression method. In our models, our student, teacher, and school covariates included the composite variables as well as additional demographic variables, such as teachers' years of experience and schools' percentage of students identified as minority. (For more details, such as the descriptive statistics for the demographic and control variables, see Harbour et al., 2018).

\footnotetext{
${ }^{3}$ Weights were incorporated into all analyses to attempt to ensure that the results were representative of the targeted populations by taking the disproportionate representation of students into account during the estimation processes (National Center for Education Statistics [NCES], 2009).
} 
Table 2. Final Components Resulting from PCA of Student and Teacher Variables

\begin{tabular}{|c|c|}
\hline Variable Name & Variable Description \\
\hline \multicolumn{2}{|c|}{ Student Component 1: Students' opinions of mathematics and mathematics class $(\alpha=.971)$} \\
\hline M824701 & Like math \\
\hline M824801 & Math is a favorite subject \\
\hline M824401 & Like what is done in math class \\
\hline \multicolumn{2}{|c|}{ Student Component 2: Students' use of technology for mathematics ( $\alpha=.847$ ) } \\
\hline M814301 & Use computer at school for math \\
\hline M823901 & Use computer at home for math homework \\
\hline M814601 & Use computer to practice or drill on math \\
\hline M814701 & Use computer to play math games \\
\hline M814501 & Use computer to make charts or graphs for math \\
\hline M814901 & Use the Internet to learn things about math \\
\hline \multicolumn{2}{|c|}{ Student Component 3: Students' attitudes or self-efficacy about mathematics $(\alpha=.963)$} \\
\hline M824201 ${ }^{\mathrm{a}}$ & Math work is too hard \\
\hline M824301 & Math work is too easy \\
\hline \multicolumn{2}{|c|}{ Teacher Component 1: Differentiated Instructional Practices $(\alpha=.969)$} \\
\hline T044201 & Create groups in math class based on ability \\
\hline T106801 & Teaching math-set different standards for some students \\
\hline T106802 & Teaching math-use other materials some students \\
\hline T106803 & Teaching math-engage some students in different activities \\
\hline T106804 & Teaching math-use different methods for some students \\
\hline T106805 & Teaching math-change pace for some students \\
\hline \multicolumn{2}{|c|}{ Teacher Component 2: Amount of emphasis on certain content areas $(\alpha=.982)$} \\
\hline T075352 & Emphasis on measurement \\
\hline T075353 & Emphasis on geometry \\
\hline T075354 & Emphasis on data analysis \\
\hline T075355 & Emphasis on algebra and functions \\
\hline \multicolumn{2}{|c|}{ Teacher Component 3: Students use of computers for mathematics $(\alpha=.979)$} \\
\hline T106601 & Students use computer to practice/review math \\
\hline T016602 & Students use computer to extend math learning \\
\hline T106609 & Students use computer to play math games \\
\hline \multicolumn{2}{|c|}{ Teacher Component 4: Practices used to meet the needs of individual students $(\alpha=.981)$} \\
\hline T107001 & Individual math students-discuss current performance level \\
\hline T107002 & Individual math students-set goals for specific program \\
\hline T107003 & Individual math students-discuss progress toward goal \\
\hline T107004 & Individual math students-adjust teaching strategies to meet needs of students \\
\hline \multicolumn{2}{|c|}{ Teacher Component 5: Assessment practices used in the classroom $(\alpha=.899)$} \\
\hline T047402 & Assess math with problem sets \\
\hline T047403 & Assess math with short or long written responses \\
\hline T057404 & Assess math with individual or group projects \\
\hline
\end{tabular}

\section{DATA ANALYTIC TECHNIQUES}

In this study, we explored the relationship between principal-reported time spent on the six different responsibilities of fulltime MCSs (see Table 1) and fourth-grade students' overall mathematics achievement (i.e., composite score), as well as mathematics achievement in the five content areas as defined in the NAEP dataset (i.e., number properties and operations; measurement; geometry; data analysis, statistics, and probability; and algebra). This examination was exploratory in nature and did not include a comparison group. To explore the relationship between full-time MCSs' responsibilities and fourth-grade students' mathematics achievement, a model-based approach (i.e., hierarchical linear modeling, or HLM; Raudenbush \& Bryk, 2002) was used as it allowed for adjustments for the effects of covariates and addressed the nested nature of the data (McCoach \& Adelson, 2010). Specifically, a two-level HLM, with the responsibilities as Level-2 predictors, was used to examine these relationships. Composite covariates and control variables were appropriately modeled at Level 1 and Level 2 prior to the inclusion of the MCS responsibility variable. Each responsibility was included as a Level-2 predictor of mathematics achievement (composite score, as well as the five content areas) one at a time in order to determine the specific relationships and to account for multicollinearity between the different responsibilities. All composite and control variables remained in the models, regardless of statistical significance to enable comparisons of results across the six measures of mathematics achievement and the six responsibilities of MCSs.

To account for the frequent problem of missing data in large-scale data sets, multiple imputation (MI; MI=5) was used in order to address this concern from the onset and move forward with complete-data methods of analysis (Rubin, 1987; Schafer, 1999). MI was conducted using SPSS Version 22 wherein plausible values were imputed for missing data in the original dataset, excluding treatment and outcome variables (McKnight \& McKnight, 2011; Rubin, 1987). We proceeded with the assumption that data were 
missing at random, as this was realistic assumption based on the proportion of missing data (1.78\%) being very small (Raudenbush \& Bryk, 2002).

For each of the achievement outcomes, we used the same final contextual model, which allowed the intercept and students' disability status (IEP status) to vary between groups but did not allow the variances of the other school-and student-level control variables to randomly vary (for more details on the model-building process and centering decisions, see Harbour et al., 2018). This contextual model, without MCS responsibilities (the treatment variables) is shown in Equation 1:

$$
\begin{aligned}
& \text { COMP }_{i j}=\gamma_{00}+\gamma_{01}{ }^{*} \text { PUBPRIV }_{j}+\gamma_{02}{ }^{*} \text { PERFRL }_{j}+\gamma_{03}{ }^{*} \text { PERMINOR }_{j}+\gamma_{04}{ }^{*} \text { PERLEP }_{j}+\gamma_{05}{ }^{*} \text { PERGIFTE }_{j}+ \\
& \gamma_{06}{ }^{*} \text { PERSPED }_{j}+\gamma_{10}{ }^{*} \text { GENDER }_{i j}+\gamma_{20}{ }^{*} \text { MINORITY }_{i j}+\gamma_{30}{ }^{*} \text { LEP }_{i j}+\gamma_{40}{ }^{*} D A Y S A B S_{i j}+\gamma_{50}{ }^{*} \text { LIKEMATH }_{i j}+ \\
& \gamma_{60}{ }^{*} \text { TECHMATH }_{i j}+\gamma_{70}{ }^{*} \text { SELFEFF }_{i j}+\gamma_{80}{ }^{*} \text { YRSEXP }_{i j}+\gamma_{90}{ }^{*} \text { MTHDGRE }_{i j}+\gamma_{100}{ }^{*} \text { DIFFINST }_{i j}+\gamma_{110}{ }^{*} \text { EMPCONT }_{i j}+
\end{aligned}
$$

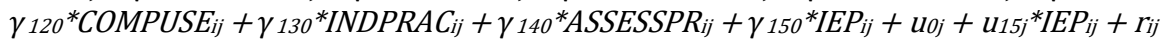

where $\mathrm{COMP}_{i j}$ is the averaged plausible value composite mathematics score for student $i$ in school $j$. For each of the five content areas, we used the same contextual model except we substituted the specific content outcome for COMP $i j$ as the outcome variable in the equation. The student-level control variables are public/private school; percent of students receiving free/reduced-price lunch, identifying as a racial/ethnic minority, with limited English proficiency, identified gifted, and receiving special education services; gender; whether they identified as a racial/ethnic minority; whether they had limited English proficiency; the number of days they were absent last month; the composite covariates related to liking math, use of technology for math, and attitudes or self-efficacy towards math; and IEP status. The teacher-level control variables are years of experience; having a math degree; and the composite covariates related to differentiated instructional practices, amount of emphasis on content areas, student use of computers for mathematics, practices used to meet the individual needs of students, and assessment practices in the classroom.

To examine the relationship between principal-reported time spent on the six responsibilities of full-time MCSs and fourth grade students' mathematics achievement on the NAEP, each responsibility was added as a predictor of the intercept one at a time for each content area. Equation 2 illustrates the final contextual model estimating fourth-grade students' mathematics achievement after the inclusion of one treatment variable (i.e., RESPONSIBILITY1, RESPONSIBILITY2, RESPONSIBILITY3, etc.):

$$
\begin{aligned}
& \mathrm{COMP}_{i j}=\gamma_{00}+\gamma_{01} * \mathrm{PUBPRIV}_{j}+\gamma_{02}{ }^{*} \mathrm{PERFRL}_{j}+\gamma_{03}{ }^{*} \mathrm{PERMINOR}_{j}+\gamma_{04}{ }^{*} \mathrm{PERLEP}_{j}+\gamma_{05}{ }^{*} \mathrm{PERGIFTE}_{j}+ \\
& \gamma_{06}{ }^{*} \text { PERSPED }_{j}+\gamma_{07}{ }^{*} \text { RESPONSBILITY } 1_{j}+\gamma_{10}{ }^{*} \text { GENDER }_{i j}+\gamma_{20}{ }^{*} \text { MINORITY }_{i j}+\gamma_{30}{ }^{*} \text { LEP }_{i j}+\gamma_{40}{ }^{*} D A Y S A B S_{i j}+ \\
& \gamma_{50}{ }^{*} \text { LIKEMATH }_{i j}+\gamma_{60}{ }^{*} \text { TECHMATH }_{i j}+\gamma_{70}{ }^{*} \text { SELFEFF }_{i j}+\gamma_{80}{ }^{*} \text { YRSEXP }_{i j}+\gamma_{90}{ }^{*} \text { MTHDGRE }_{i j}+\gamma_{100}{ }^{*} \text { DIFFINST }_{i j}+ \\
& \gamma_{110^{*} E M P C O N T}+\gamma_{120}{ }^{*} \text { COMPUSE }_{i j}+\gamma_{130}{ }^{*} I N D P R A C_{i j}+\gamma_{140}{ }^{*} \text { SSSESSPR }_{i j}+\gamma_{150}{ }^{*} I E P_{i j}+u_{0 j}+u_{15 j}{ }^{*} I E P_{i j}+r_{i j}
\end{aligned}
$$

where $\operatorname{COMP}_{i j}$ is the averaged plausible value composite mathematics score for student $i$ in school $j, \gamma_{07}$ is the differential in composite score based on extent to which the full-time MCS engages in providing technical assistance/support to individual teachers about mathematics content or the teaching of mathematics. Similar equations for the remaining six responsibilities and five content areas were used (substituting the specific content outcome variable into the equation for $\operatorname{COMP}_{i j}$ and the specific responsibility of the MCS in for RESPONSIBILITY1 $1_{j}$ ).

\section{RESULTS}

Table 1 provides the weighted descriptive statistics for MCSs' six NAEP-defined responsibilities as reported on the school survey (i.e., principal-reported measure). A simple examination of descriptive statistics revealed that principals of schools with full-time MCSs reported that MCSs, on average, allocated a moderate to large extent of time on providing technical assistance/support to individual teachers about mathematics content or the teaching of mathematics (i.e., Responsibility 1); a moderate extent of time conducting professional development for groups of teachers about mathematics content or the teaching of mathematics (i.e., Responsibility 2), providing mathematics instruction to students on various topics (i.e., Responsibility 3), providing mathematics instruction to students at various grade levels (i.e., Responsibility 4), and providing mathematics remediation/intervention to some student groups (i.e., Responsibility 5); and, a small to moderate extent of time providing mathematics enrichment to some student groups (i.e., Responsibility 6). However, it should be noted that these measurements on the extent of time MCSs spend on each responsibility were not proportional in nature, meaning the extent of time spent on each responsibility was measured independently; thus, it cannot be assumed that the measurements represented the percent of time MCSs engaged in each responsibility.

Next, we present the results from each multi-level modeled analyses for the relationships among the six MCS responsibilities (see Table 3) and fourth-grade students' mathematics achievement, including overall achievement and five content domains (i.e., number properties and operations; measurement; geometry; data analysis, statistics, and probability; and algebra).

\section{Relationship between MCS Responsibility 1 and Mathematics Achievement}

The responsibility of providing technical assistance/support to individual teachers about mathematics content or the teaching of mathematics (i.e., Responsibility 1$)$ had a statistically significant relationship $(p<.05)$ with fourth-grade students' composite (i.e., overall) mathematics achievement (coefficient $=0.80, S E=0.36, p=.032$ ), measurement achievement (coefficient $=1.26, S E=$ $0.46, p=.007$ ), and geometry achievement (coefficient $=1.14, S E=0.38, p=.004$; see Table 3 ). On average, these results indicate MCSs' responsibility of providing technical assistance/support to individual teachers about mathematics content or the teaching of mathematics (i.e., Responsibility 1 ) in schools is related to higher achievement in overall mathematics achievement, as well as achievement in both measurement and geometry. 
Table 3. Final Multi-level Models Examining the Relationship between Principal-Reported Time Spent on the Six Different NAEPDefined Responsibilities of Full-Time Mathematics Coaches/Specialists (MCS) and Students' Mathematics Achievement

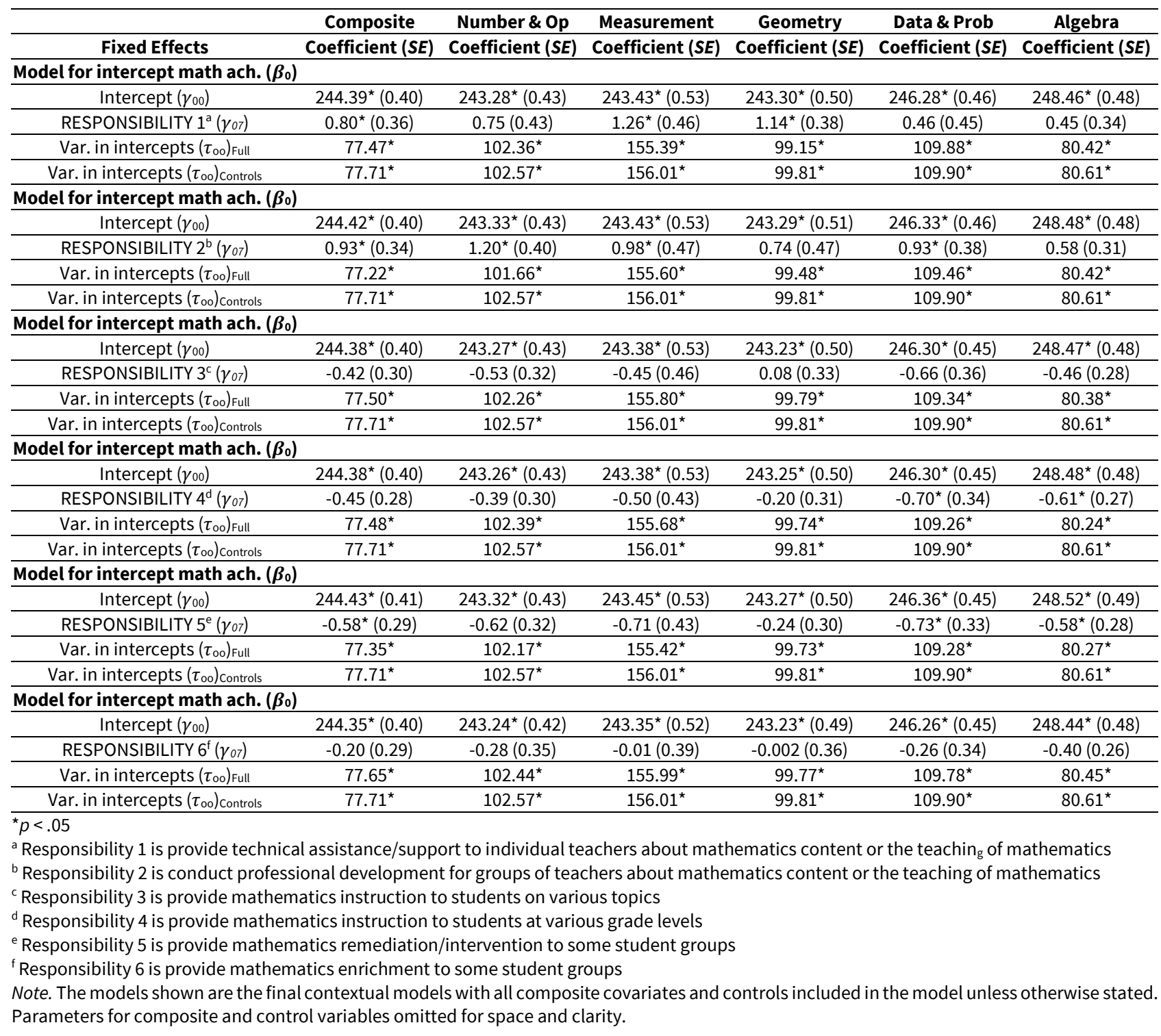

Providing technical assistance/support to individual teachers about mathematics content or the teaching of mathematics did not have a statistically significant relationship $(p>.05)$ with number properties and operations achievement, data analysis, statistics, and probability achievement, or algebra achievement on the NAEP for fourth-grade students.

\section{Relationship between MCS Responsibility 2 and Mathematics Achievement}

MCS Responsibility 2, conduct professional development for groups of teachers about mathematics content or the teaching of mathematics, had statistically significant relationships with four of the six outcome variables: composite mathematics achievement (coefficient $=0.93, S E=0.34, p=.010$ ), number properties and operations achievement (coefficient $=1.20, S E=0.40$, $p=.005$ ), measurement (coefficient $=0.98, S E=0.47, p=.043$ ), and data analysis, statistics, and probability achievement (coefficient $=0.93, S E=0.38, p=.017$; Table 3). On average, these results indicate MCSs spending more time on conducting professional development for groups of teachers about mathematics content or the teaching of mathematics (i.e., Responsibility 2) in schools is related to higher achievement in overall mathematics achievement, as well as higher achievement in number properties and operations, measurement, and in data analysis, statistics, and probability.

Conducting professional development for groups of teachers about mathematics content or the teaching of mathematics did not have a statistically significant relationship $(p>.05)$ with geometry or algebra achievement on the NAEP for fourth-grade students.

\section{Relationship between MCS Responsibility 3 and Mathematics Achievement}

Providing mathematics instruction to students on various topics (Responsibility 3) did not have a statistically significant relationship ( $p>.05$; see Table 3 ) with any of the achievement outcome measures, which included composite (overall), number properties and operations; measurement; geometry; data analysis, statistics, and probability; and algebra. This simply means that 
there is not a statistically significant relationship between the amount of time an MCS provides mathematics instruction to students on various topics and fourth-grade students' mathematics achievement on the 2011 NAEP mathematics assessment.

\section{Relationship between MCS Responsibility 4 and Mathematics Achievement}

Responsibility 4, provide mathematics instruction to students at various grade levels, had a statistically significant relationship with both data analysis, statistics, and probability achievement (coefficient $=-0.70, S E=0.34, p=.041$ ) and algebra achievement (coefficient $=-0.61, S E=0.27, p=.021$; see Table 3 ). Providing mathematics instruction to students at various grade levels did not have a statistically significant relationship $(p>.05)$ with composite achievement, measurement achievement, or geometry achievement.

\section{Relationship between MCS Responsibility 5 and Mathematics Achievement}

The responsibility of providing mathematics remediation/intervention to some student groups (i.e., Responsibility 5) had statistically significant relationships with fourth-grade students' overall (composite) mathematics achievement (coefficient $=$ $0.58, S E=0.29, p=.047$; see Table 3 ). In addition, providing mathematics remediation/intervention to some student groups was statistically associated with data analysis, statistics, and probability achievement (coefficient $=-0.73, S E=0.33, p=.031$ ) and algebra achievement (coefficient $=-0.58, S E=0.28, p=.043$ ). No statistically significant association between providing mathematics remediation/intervention to some student groups and number properties and operations, measurement, or geometry achievement was found.

As previously noted, given the correlational nature of this study, the lack of a control group for this research question, and the inability to control for achievement prior to having an MCS, directionality cannot be established for the relationship between principal-reported time spent on the responsibilities and fourth-grade students' mathematics achievement on the NAEP. For instance, given that a positive relationship between having a full-time MCS and fourth-grade students' mathematics achievement on the 2011 NAEP Mathematics Assessment has been established (Harbour et al., 2018), it is likely that schools with lower achievement require MCSs to spend more of their time on Responsibility 5 rather than the more time an MCS spends on Responsibility 5 causes achievement to decrease. Therefore, the statistically significant relationships noted likely mean that schools with lower achievement in overall scores; data analysis, statistics, and probability scores' and, algebra scores require MCSs to spend more of their time providing mathematics remediation/intervention to some student groups (i.e., Responsibility 5).

\section{Relationship between MCS Responsibility 6 and Mathematics Achievement}

Similar to the results between MCS Responsibility 3 and achievement, MCS Responsibility 6, providing mathematics enrichment to some student groups, was not statistically significantly related ( $p>.05$; see Table 3 ) to any of the achievement outcome measures (i.e., composite [overall], number properties and operations; measurement; geometry; data analysis, statistics, and probability; and algebra), meaning that there was no significant relationship between the amount of time MCSs spend providing mathematics enrichment to some student groups and fourth-grade students' mathematics achievement on the NAEP.

\section{DISCUSSION}

As previously mentioned, there is an emerging body of research exploring relationships between MCSs and mathematics student achievement. Much of this work, however, nests coaching within a larger professional development or reform effort (Balfanz et al., 2006; Campbell, 1996; Foster \& Noyce, 2004), thus making it difficult to discern the specific impact of coaching. A small group of studies has taken a critical first step in addressing this limitation (Campbell \& Malkus, 2011; Ellington et al., 2017; Harbour et al., 2018), and the present study makes a valuable contribution by providing additional evidence of the relationship between MCSs and students' mathematics achievement. In particular, the 2011 restricted-use NAEP Mathematics data were used to explore principal-reported time spent on the six different NAEP-defined responsibilities of full-time MCSs and fourth-grade students' mathematics achievement. As the six NAEP-defined responsibilities can be sub-divided into two broad categories (supporting teachers and supporting students), we summarize the main findings for each broad category below.

\section{Supporting Teachers}

Overall, statistically significant positive relationships were found between full-time MCSs' responsibilities of both of the variables related to supporting teachers, including, supporting individual and groups of teachers and fourth-grade students' composite (i.e., overall) mathematics achievement (as well as varied content domains). In other words, on average, as MCSs spend more time working with individual and/or groups of teachers, higher overall mathematics achievement can be expected for fourthgrade students. Furthermore, a slightly stronger statistical relationship was noted between supporting groups of teachers and fourth-grade students' overall mathematics achievement, than it was for supporting individual teachers and fourth-grade students' overall mathematics achievement (see Tables 3 and 4). However, we note that these differences were minimal and should be interpreted cautiously and with the understanding that both have statistically significant positive relationships with students' overall mathematics achievement, lending to the idea that both are likely worthwhile endeavors. 
Table 4.Statistically Significant Relationships between Principal-reported Time Spent on the NAEP-defined Mathematics Coaches/Specialists (MCS) Responsibilities and Fourth-Grade Students' Mathematics Achievement

\begin{tabular}{|c|c|c|c|c|c|c|}
\hline MCS Responsibility & $\begin{array}{l}\text { Composite } \\
\text { (overall) }\end{array}$ & Number ${ }^{\mathrm{a}}$ & Measurement & Geometry & Data $^{b}$ & Algebra \\
\hline \multicolumn{7}{|l|}{ Teacher-focused } \\
\hline $\begin{array}{c}\text { Provide technical assistance/support to individual teachers about } \\
\text { mathematics content or the teaching of mathematics (Responsibility 1) }\end{array}$ & + & & + & + & & \\
\hline $\begin{array}{c}\text { Conduct professional development for groups of teachers about } \\
\text { mathematics content or the teaching of mathematics (Responsibility 2) }\end{array}$ & + & + & + & & + & \\
\hline \multicolumn{7}{|l|}{ Student-focused } \\
\hline $\begin{array}{l}\text { Provide mathematics instruction to students at various grade levels } \\
\text { (Responsibility 4) }\end{array}$ & & & & & - & - \\
\hline $\begin{array}{l}\text { Provide mathematics remediation/intervention to some student groups } \\
\text { (Responsibility 5) }\end{array}$ & - & & & & - & - \\
\hline
\end{tabular}

\section{Supporting Students}

In regard to working with students, either no statistically significant relationships or statistically significant negative relationships were found between full-time MCSs' time allocation spent working with students and fourth-grade students' mathematics achievement (see Tables 3 and 4). Specifically, when MCSs provided the following types of supports to students, no statistically significant relationships with overall or content domain fourth-grade students' mathematics achievement were noted: (a) providing mathematics instruction to students on various topics, and (b) providing mathematics enrichment to some student groups. Conversely, statistically significant negative relationships were found between MCSs' time allocation spent providing mathematics instruction to students at various grade levels and fourth-grade students' data analysis and algebra achievement. Additionally, a statistically significant negative relationship occurred between MCSs' time allocation spent providing mathematics remediation/intervention to some student groups and fourth-grade students' overall mathematics achievement, as well as achievement in data analysis and algebra domains. However, similar to significant relationships with MCSs' work with teachers, these results must be interpreted with caution as they are correlational in nature. For instance, rather than interpreting the relationship as MCSs who spend more time providing mathematics remediation/intervention to some groups of students are likely to see lower mathematics achievement in schools, the relationship could be interpreted as MCSs in schools with lower mathematics achievement are more likely to spend their time providing mathematics remediation/intervention to some student groups.

\section{Situating the Results in Literature}

MCSs have many responsibilities when striving to support the teaching and learning of mathematics (Mudzimiri et al., 2014). Generally-speaking, these responsibilities involve supporting individual (Neuberger, 2012; Polly, 2012) and groups (Elliott et al., 2009; Lesseig et al., 2017) of teachers, as well as supporting students (Chval et al., 2010; Fennell, 2017). In relation to these responsibilities, some research has focused on MCSs' time allocation, finding that MCSs may spend more time supporting individuals rather than groups of teachers (Bean et al., 2010; Campbell \& Griffin, 2017; Deussen et al., 2007; Lord et al., 2008) and that MCSs may consistently spend time each day supporting students (Campbell \& Griffin, 2017; Ellington et al., 2017). However, absent from the literature is an understanding of the relationship between MCSs' time spent engaged in these responsibilities and student mathematics achievement. In other words, when supporting teaching and learning, is it more productive for MCSs to engage in one responsibility (e.g., supporting groups of teachers) versus another (e.g., providing mathematics remediation to students)? Gibbons and Cobb (2017) took a vital first step in answering this question with their conceptual piece as they identified individual and group coaching activities backed by a research base demonstrating their positive impact on teachers and students. This conceptual piece set the stage for follow-up empirical work, including the current study. Specifically, our study makes a contribution by suggesting that it may be beneficial to have MCSs spend significant time with teachers, providing assistance, support, and professional development, and that when standardized measures of achievement are low, schools use MCSs to work with students mostly providing remediation and intervention (see Tables 3 and 4).

\section{Limitations}

Although our work adds to the current literature base on MCSs by exploring relationships among MCSs responsibilities and fourth-grade students' mathematics achievement, similar to most research, our work has limitations that should be considered as conclusions are interpreted. Even though using a large-scale dataset provides a way to explore these relationships using a nationally representative sample and the ability to control for many variables, it does come with restrictions based upon data collection. First, the data pertaining to MCSs were collected using the school survey. Because of this, results were determined based on how the principal or assistant principal viewed the responsibility of the MCS in their particular school. Findings could be influenced based on who provides this information. Second, as with any secondary data analysis, we were limited by the variables available to us (i.e., those that NCES collected data on). In particular, we lacked more detail about the MCSs, particularly how long they were an MCS as their school, their background and demographic characteristics, how much time they spent with grade levels or student groups, and the proportion of time they engaged in each of the MCS responsibilities. The addition of these variables 
would allow for more in-depth analyses. Third, as research indicates that MCSs are often called upon to fulfill other responsibilities that are not directly related to supporting teaching and learning (Chval et al., 2010; Kane \& Rosenquist, 2018; Matsumura et al., 2009; Saclarides \& Lubienski, 2020), the NAEP survey question should be changed to encompass all responsibilities, instead of only those specific to supporting teaching and learning. Fourth, the current study's design limits the findings to correlational in nature. We employed a large number of composite covariates and control variables in the models to strengthen the design; however, casual inferences cannot be drawn.

\section{Future Direction}

Given findings from the current study, as well as the limitations mentioned above, we offer suggestions for future research in two key areas: (1) quantitative data collection regarding MCSs' work, and (2) other macro- and micro-level methodological considerations.

As the impact of how MCSs spend their time and how that influences student achievement is vital, a measure to address the proportionality of time MCSs engage in certain activities is needed. Using the NAEP-defined responsibilities provides researchers with a solid foundation on which to build upon; by simply adding in different responsibilities, such as administrative tasks and an "other" category to capture nuanced work, along with additional responsibilities reviewed in the literature, more detailed data can be collected quantitatively on a large scale. Furthermore, a change in the scale used to measure the extent of time spent on each responsibility to represent a proportional value that would sum to $100 \%$ is critical. A survey measuring the responsibilities proportionally (i.e., totaling 100) would provide the needed information to address pressing questions such as: what is the most effective responsibility, or use of time, for MCSs? Does working with students or teachers have a greater impact on students' mathematics achievement? Lastly, future data collection should allow the MCS at each school to answer all questions pertaining to their time spent in various responsibilities in order strengthen the validity of conclusions drawn from these variables.

Although findings indicate that there are positive and significant relationships between MCSs' time spent supporting individual and groups of teachers and mathematics student achievement, additional research is still needed to better understand these complex relationships. At the macro-level, quantitative researchers could consider using an experimental design to further establish causal links, as well as develop measures for survey data collection noted above. Additionally, questions as to what this looks like at the micro-level for coaches and teachers still remain. This line of empirical work might be extended through qualitative explorations of how accomplished MCSs support individual and groups of teachers in ways that are productive and enhance teacher and student learning of mathematics.

\section{CONCLUSION}

This study used the restricted-use, nationally representative data from the 2011 NAEP mathematics assessment to explore the relationships among principal-reported time of full-time MCSs' responsibilities and fourth-grade students' mathematics achievement (overall mathematics achievement and achievement across the five content areas). We found statistically significant positive relationships between full-time MCSs' responsibilities of supporting individual and groups of teachers and fourth-grade students' composite (i.e., overall) mathematics achievement (as well as in varied content domains). Additionally, we found either no statistically significant relationship or statistically significant negative relationships between MCSs' time allocation spent working with students and fourth-grade students' mathematics achievement, although these results should be interpreted with caution. This study's results provide evidence on which responsibilities MCSs engage in may be most impactful in relation to students' mathematical achievement. Even so, as the link between MCSs' responsibilities and student achievement is an area of limited examination, additional research is needed to establish casual relationships among MCSs' responsibilities and students' achievement, including research to determine the most influential responsibilities MCSs can engage in to support students' mathematics achievement.

Author contributions: All authors have sufficiently contributed to the study, and agreed with the results and conclusions.

Funding: No funding source is reported for this study.

Declaration of interest: No conflict of interest is declared by authors.

\section{REFERENCES}

Ai, X., \& Rivera, N. (2003). Linking ideas to practice: Effectiveness of coaching upon teacher practice [Paper presentation]. Annual meeting of the American Educational Research Association, April 23, Chicago, IL.

Alloway, M., \& Jilk, L. M. (2010). Supporting students by supporting teachers: Coaching moves that impact learning. In P. Brosnan, D. B. Erchick, \& L. Flevares (Eds.), Proceedings of the $32^{\text {nd }}$ annual meeting of the North American Chapter of the International Group for the Psychology of Mathematics Education (Volume VI, p. 1420-1427). The Ohio State University.

Baldinger, E. M. (2014, April). Learning together: Looking for learning in coach-teacher interactions. National Council of Teachers of Mathematics Research Conference, New Orleans, LA.

Balfanz, R., Mac Iver, D. J., \& Byrnes, V. (2006). The implementation and impact of evidence-based mathematics reforms in high poverty middle schools: A multi- site, multi-year study. Journal for Research in Mathematics Education, 37, 33-64. https://doi.org/10.2307/30035051 
Barlow, A. T., Burroughs, E. A., Harmon, S. E., Sutton, J. T., \& Yopp, D. A. (2014). Assessing views of coaching via a video-based tool. ZDM, 46, 227-238. https://doi.org/10.1007/s11858-013-0558-7

Bean, R. M., Draper, J. A., Hall, V., Vandermolen, J., \& Zigmond, N. (2010). Coaches and coaching in reading first schools. The Elementary School Journal, 111(1), 87-114. https://doi.org/10.1086/653471

Becker, J. R. (2001). Classroom coaching: An emerging method of professional development. In R. Speiser, C. Maher \& C. Walter (Eds.), Proceedings of the Twenty-third Annual Meeting of the North American Chapter of the International Group for the Psychology of Mathematics Education (Vol. 2, pp. 751-760). Snowbird, UT.

Campbell, P. F. (1996). Empowering children and teachers in the elementary mathematics class- rooms of urban schools. Urban Education, 30, 449-475. https://doi.org/10.1177/0042085996030004005

Campbell, P. F., \& Malkus, N. N. (2011). The impact of elementary mathematics coaches on student achievement. The Elementary School Journal, 111, 430-454. https://doi.org/10.1086/657654

Chval, K. B., Arbaugh, F., Lannin, J. K., van Garderen, D., Cummings, L., Estapa, A. T., \& Huey, M. E. (2010). The transition from experienced teacher to mathematics coach: Establishing a new identity. The Elementary School Journal, 111, $191-216$. https://doi.org/10.1086/653475

Collins, A., Brown, J. S., \& Newman, S. E. (1987). Cognitive apprenticeship: Teaching the crafts of reading, writing, and mathematics (Technical Report No. 403). National Institute of Education. Retrieved from http://files.eric.ed.gov/fulltext/ED284181.pdf

Desimone, L. M. (2009). Improving impact studies of teachers' professional development: Toward better conceptualizations and measures. Educational Researcher, 38, 181-199. https://doi.org/10.3102/0013189X08331140

Desimone, L. M., \& Pak, K. (2017). Instructional coaching as high-quality professional development. Theory into Practice, 56(1), 312. https://doi.org/10.1080/00405841.2016.1241947

Deussen, T., Coskie, T., Robinson, L., \& Autio, E. (2007). “Coach” can mean many things: Five categories of literacy coaches in Reading First (Issues \& Answers Report, REL 2007-No. 005). U.S. Department of Education, Institute of Education Sciences, National Center for Education Evaluation and Regional Assistance, Regional Educational Laboratory Northwest.

Ellington, A., Whitenack, J., \& Edwards, D. (2017). Effectively coaching middle school teachers: A case for teacher and student learning. The Journal of Mathematical Behavior, 46, 177-195. https://doi.org/10.1016/j.jmathb.2016.12.012

Elliott, R., Kazemi, E., Lesseig, K., Mumme, J., Carroll, C., \& Kelley-Petersen, M. (2009). Conceptualizing the work of leading mathematical tasks in professional development. Journal of Teacher Education, 60, 364-379. https://doi.org/10.1177/0022487109341150

Fennell, F. (2017). We need mathematics specialists now: A historical perspective and next steps. In M. B. McGatha \& N. R. Rigelman (Eds.), Elementary mathematics specialists: Developing, refining, and examining programs that support mathematics teaching and learning (pp. 3-18). Information Age Publishing, Inc.

Foster, D. \& Noyce, P. (2004). The mathematics assessment collaborative: Performance testing to improve instruction. Phi Delta Kappan, 85, 367-374. https://doi.org/10.1177/003172170408500507

Gerretson, H., Bosnick, J., \& Schofield, K. (2008). A case for content specialists as the elementary classroom teacher. The Teacher Educator, 43, 302-314. https://doi.org/10.1080/08878730802249866

Gibbons, L. K., \& Cobb, P. (2017). Focusing on teacher learning opportunities to identify potentially productive coaching activities. Journal of Teacher Education, 68, 411-425. https://doi.org/10.1177/0022487117702579

Gibbons, L. K., Kazemi, E., Hintz, A., \& Hartmann, E. (2017). Teacher time out: Educators learning together in and through practice. Journal of Mathematics Educational Leadership, 18, 28-46.

Gibbons, L. K., Kazemi, E., \& Lewis, R. M. (2017). Developing collective capacity to improve mathematics instruction: Coaching as a lever for school-wide improvement. The Journal of Mathematical Behavior, 46, $231-250$. https://doi.org/10.1016/j.jmathb.2016.12.002

Goodman, T., McCoy, A., \& Campbell, L. (2017). A collaborative model: From establishing certification to developing and delivering a program. In M. B. McGatha \& N. R. Rigelman (Eds.), Elementary mathematics specialists: Developing, refining, and examining programs that support mathematics teaching and learning (pp. 61-68). Information Age Publishing, Inc.

Harbour, K. E., Adelson, J. L., Karp, K. S., Pittard, C. M. (2018). Examining the relationships among mathematics coaches and specialists, student achievement, and disability status: A multi-level analysis using National Assessment of Education Progress data. The Elementary School Journal, 118(4), 654-679. https://doi.org/10.1086/697529

Harrington, R. A., Burton, L., \& Beaver, C. (2017). Answering the call by developing an online elementary mathematics specialist program. The Journal of Mathematical Behavior, 46, 303-312. https://doi.org/10.1016/j.jmathb.2017.01.001

Haver, W. E., Trinter, C. P., \& Inge, V. L. (2017). The Virginia mathematics specialist initiative: Collaborative effort among all components of the VA mathematics community. The Journal of Mathematical Behavior, 46, $289-302$. https://doi.org/10.1016/j.jmathb.2016.12.003

Hopkins, M., Ozimek, D., \& Sweet, T. M. (2017). Mathematics coaching and instructional reform: Individual and collective change. The Journal of Mathematical Behavior, 46, 215-230. https://doi.org/10.1016/j.jmathb.2016.11.003

Kane, B. D., \& Rosenquist, B. (2019). Relationships between instructional coaches' time use and district-and school-level policies and expectations. American Educational Research Journal, 56, 1718-1768. https://doi.org/10.3102/0002831219826580 
Lesseig, K., Elliott, R., Kazemi, E., Kelley-Petersen, M., Campbell, M., Mumme, J., \& Carroll, C. (2017). Leader noticing of facilitation in videocases of mathematics professional development. Journal of Mathematics Teacher Education, 20, 591-619. https://doi.org/10.1007/s10857-016-9346-y

Matsumura, L. C., Sartoris, M., Bickel, D. D., \& Garnier, H. E. (2009). Leadership for literacy coaching: The principal's role in launching a new coaching program. Educational Administration Quarterly, 45, 655-693. https://doi.org/10.1177/0013161X09347341

McCoach, D. B., \& Adelson, J. L. (2010). Dealing with dependence (Part 1): Understanding the effects of clustered data. Gifted Child Quarterly, 54, 152-155. https://doi.org/10.1177/0016986210363076

McGatha, M. (2008). Levels of engagement in establishing coaching relationships. Teacher Development, 12, 139-150. https://doi.org/10.1080/13664530802038147

McGatha, M. B., \& Rigelman, N. R. (2017). Introduction. In M. B. McGatha \& N. R. Rigelman (Eds.), Elementary mathematics specialists: Developing, refining, and examining programs that support mathematics teaching and learning (pp. xiii-xv). Information Age Publishing, Inc.

McGatha, M. B., Davis, R., \& Stokes, A. (2015). The impact of mathematics coaching on teachers and students (Brief). National Council of Teachers of Mathematics.

McKnight, P.E. \& McKnight, K.M. (2011). Missing data in secondary data analysis. In K. H. Trzesniewski, M. B. Donnellan, \& R. E. Lucas (Eds.), Secondary data analysis: An introduction for psychologists (p. 83-101). American Psychological Association. https://doi.org/10.1037/12350-005

Mudzimiri, R., Burroughs, E.A., Luebeck, J., Sutton, J., \& Yopp, D. (2014). A look inside mathematics coaching: Roles, content, and dynamics. Education Policy Analysis Archives, 22(53), 1-32. https://doi.org/10.14507/epaa.v22n53.2014

Munson, J. (2017). Examining the efficacy of side-by-side coaching for growing responsive teacher-student interactions in elementary classrooms. In E. Galindo \& J. Newton (Eds.), Proceedings of the $29^{\text {th }}$ Annual Meeting of the North American Chapter of the International Group for the Psychology of Mathematics Education (pp. 471-474). Hoosier Association of Mathematics Teacher Educators.

National Center for Education Statistics (2009). NAEP Technical Documentation. Institute of Education Sciences, U.S. Department of Education, Washington, D.C. http://nces.ed.gov/nationsreportcard/tdw/

National Center for Education Statistics (2011). The Nation's report card: Mathematics 2011 (NCES 2012-458). Institute of Education Sciences, U.S. Department of Education, Washington, D.C.

National Center of Education Statistics. (2013). The Nation's report card: Mathematics 2013. Institute of Education Sciences, U.S. Department of Education, Washington, D.C. http://www.nationsreportcard.gov/

National Mathematics Advisory Panel. (2008). Foundations for success: The final report of the national mathematics advisory panel. U.S. Department of Education.

Neuberger, J. (2012). Benefits of a teacher and coach collaboration: A case study. Journal of Mathematical Behavior, 31, $290-311$. https://doi.org/10.1016/j.jmathb.2011.12.004

Neufeld, B., \& Roper, D. (2003). Coaching: A Strategy for Developing Instructional Capacity: Promises \& Practicalities. Aspen Institute.

Obara, S. \& Sloan, M. (2009). The evolving role of a mathematics coach during the implementation of performance standards. Professional Educator, 33(2), 1-13.

Olson, J. C., \& Barrett, J. E. (2004). Coaching teachers to implement mathematics reform recommendations. Mathematics Teacher Education and Development, 6, 63-78.

Polly, D. (2012). Supporting mathematics instruction with an expert coaching model. Mathematics Teacher Education and Development, 14(1), 78-93.

Polly, D., Mraz, M., \& Algozzine, R. (2013). Implications for developing and researching elementary school mathematics coaches. School Science and Mathematics, 113, 297-307. https://doi.org/10.1111/ssm.12029

Race, K., Ho, E., \& Bower, L. (2002, April 1-5). Documenting in-classroom support and coaching activities of a professional development program directed toward school-wide change: An integral part of an organization's evaluation efforts [Paper presentation]. The Annual Meeting of the American Educational Research Association, New Orleans, LA.

Raudenbush, S., \& Bryk, A. (2002). Hierarchical linear models (2nd ed.). Sage.

Rigelman, N. R., \& Wray, J. A. (2017). Current state of mathematics specialist state certification and standards. In M. B. McGatha \& N. R. Rigelman (Eds.), Elementary mathematics specialists: Developing, refining, and examining programs that support mathematics teaching and learning (pp. 33-38). Information Age Publishing, Inc.

Rubin, D. B. (1987). Multiple imputation for nonresponse in surveys. John Wiley \& Sons, Inc. https://doi.org/10.1002/9780470316696

Rudd, L. C., Lambert, M. C., Satterwhite, M., \& Smith, C. H. (2009). Professional development + coaching = enhanced teaching: Increasing usage of math mediated language in preschool classrooms. Early Childhood Education Journal, 37, 63-69. https://doi.org/10.1007/s10643-009-0320-5

Saclarides, E. S., \& Lubienski, S.T. (2020). The influence of administrative policies and expectations on coach-teacher interactions. The Elementary School Journal, 120, 528-554. https://doi.org/10.1086/707196

Schafer, J. L. (1999). Multiple imputation: A primer. Statistical Methods in Medical Research, 8, 3-15. https://doi.org/10.1177/096228029900800102 
Schwartz, C. S., Morge, S. P., Rachlin, S. L., \& Hargrove, T. Y. (2017). A blended online model for instruction. In M. B. McGatha \& N. R. Rigelman (Eds.), Elementary mathematics specialists: Developing, refining, and examining programs that support mathematics teaching and learning (pp. 69-76). Information Age Publishing, Inc.

Stevens, J. P. (2009). Applied multivariate statistics for the social sciences (5 $5^{\text {th }}$ ed.). Routledge.

Strutchens, M. E., \& Martin, G. (2017). A case for secondary mathematics coaches. In M. B. McGatha \& N. R. Rigelman (Eds.), Elementary mathematics specialists: Developing, refining, and examining programs that support mathematics teaching and learning (pp. 77-84). Information Age Publishing, Inc.

Webel, C., Conner, K. A., Sheffel, C., Tarr, J. E., \& Austin, C. (2017). Elementary mathematics specialists in "departmentalized" teaching assignments: Affordances and constraints. The Journal of Mathematical Behavior, 46, $196-214$. https://doi.org/10.1016/j.jmathb.2016.12.006 